\title{
THE CESOPHAGEAL PULSE IN MITRAL VALVE DISEASE
}

BY

\author{
MAX ZOOB* \\ From the Cardiac Department of the Royal Free Hospital \\ Received February 21, 1953
}

The diagnosis of mitral incompetence, either alone or in association with mitral stenosis, often presents difficulties. In the present study an attempt has been made to provide a graphic method of confirming the diagnosis. Abnormal auricular filling consequent on reflux from the ventricle might be expected to produce abnormal movements of the contiguous portion of the esophagus and to result in an œsophageal pulse record demonstrably different from the normal.

Previous studies, however, have yielded conflicting opinions as to the diagnostic value of œsophageal pulse records. Rautenberg (1907), Lian (1909), Janowski (1910), Edens (1910), and Bard (1912) concluded that there was no curve characteristic of mitral incompetence. On the other hand Taquini (1937 and 1940) and Puddu and Sibilia (1942) described an abnormal short positive systolic wave which they considered diagnostic of the condition. Lasser et al. (1952) stated that characteristic curves were produced by each of three conditions, namely pure mitral incompetence, pure mitral stenosis, and mitral stenosis with incompetence. The methods of previous investigators have usually included the use of an œsophageal sound of $5 \mathrm{~mm}$. or more internal diameter and the recording of the jugular phlebogram as a reference tracing. The former may have caused Lewis (1925) and others in this country to conclude that the procedure was impracticable in clinical medicine, while the variability and time lag of the latter may have been the cause of the difficulty in distinguishing normal from abnormal curves. The problem has, therefore, been re-examined using a different technique.

\section{METHOD}

The passage of a Ryle's tube is generally considered to be a trivial procedure. Such a tube was adapted in the manner shown in Fig. 1 to permit the simultaneous registration of the osophageal pulse and electrocardiogram. The tube was graduated in centimetres and its tip was replaced by a $2 \mathrm{~cm}$. length of soft rubber tubing (Dunhill's thyroid drainage tubing) sealed at its end. The tubing was easily compressible and its lumen communicated with a tambour on which was mounted a needle moving in the electrocardiograph beam. The overall lag of this system was found to be about $0.01 \mathrm{sec}$. Pressure on the tip resulted in an upward deflection in the record.

An œsophageal electrode consisting of a German silver band was mounted immediately above the soft rubber tubing. Its wire passed through the lumen of the Ryle's tube to the electrocardiograph. The electrode enabled the position of the tip to be seen at fluoroscopy. The presence of

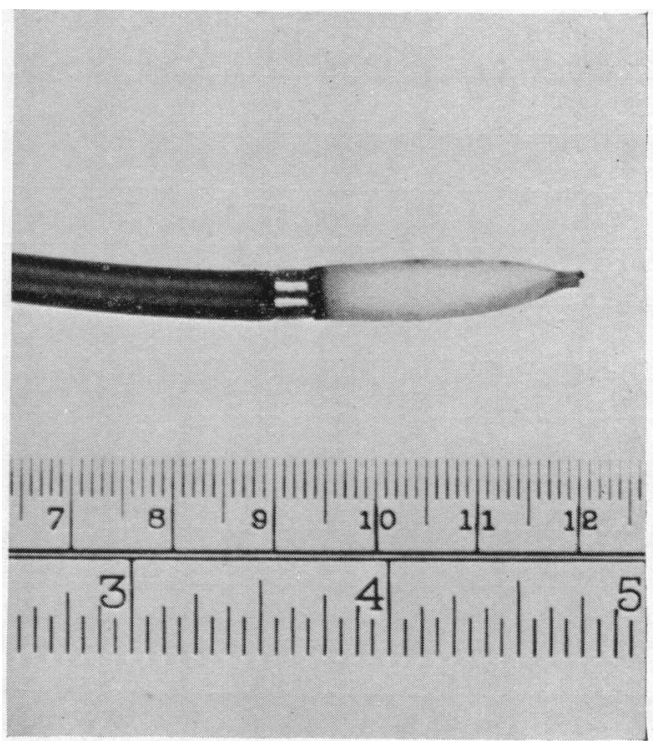

FIG. 1.-The modified Ryle's tube.

* Now at the British Postgraduate Medical School, London. 
a $P$ wave showing an intrinsicoid deflection in the finished record confirmed that the latter had been made at an auricular level (Brown, 1936) and served as a reference tracing for auricular systole. A phonocardiogram recorded electrically from the chest wall was chosen as the most direct indicator of mechanical ventricular events.

Procedure. The tube is passed to its full length and then withdrawn under fluoroscopic control. The levels at which the electrode reaches the diaphragm, lower and upper portions of the auricle, and aortic arch are noted. The tube is passed once more to its full length and records are made at $1-\mathrm{cm}$. intervals from the level of the diaphragm to the upper limit of the auricle and then at 2-cm. intervals until the aortic arch is reached.

\section{MATERIAL}

In all 119 subjects were studied. There were nearly equal numbers of patients with and without mitral valve disease, the latter serving as controls. Congestive failure was present in only one case. A complete cardiological examination, including fluoroscopy and a nine or twelve lead electrocardiogram, served as the basis for the following grouping.

Group I. Consisted of 27 normal subjects.

Group II. Thirteen patients who had left ventricular hypertrophy due either to hypertensive heart disease or to aortic valve disease.

Group III. Fifteen patients who had auricular fibrillation. Five had lone auricular fibrillation, and the remainder had hypertensive heart disease. One had ischæmic as well as hypertensive heart disease and chronic congestive failure.

Group IV. Nine patients who were thought to have innocent apical systolic murmurs. They presented no cardiac abnormality other than a systolic murmur of Grade I or II intensity (Levine, 1933).

Group V. Fourteen patients with sinus rhythm were thought to have pure mitral incompetence. The clinical findings in these fourteen are set out in Table I.

TABLE I

Clinical Findings and Gesophageal Pulse in 14 Patients with Mitral Incompetence

\begin{tabular}{|c|c|c|c|c|c|c|c|c|c|c|c|}
\hline \multirow{2}{*}{ Case } & \multirow{2}{*}{ Age } & \multirow{2}{*}{ R.F. } & \multirow{2}{*}{ Blood pressure } & \multirow{2}{*}{$\begin{array}{l}\text { Apical } \\
\text { S.M. } \\
\text { grade }\end{array}$} & \multirow{2}{*}{$\begin{array}{c}\text { Apical } \\
\text { thrill }\end{array}$} & \multicolumn{4}{|c|}{ Fluoroscopy } & \multirow{2}{*}{$\begin{array}{c}\text { Electro- } \\
\text { cardiogram }\end{array}$} & \multirow{2}{*}{$\begin{array}{l}\text { Esophageal } \\
\text { pulse }\end{array}$} \\
\hline & & & & & & L.A. & L.V. & R.A. & R.V. & & \\
\hline 1 & 19 & + & $110 / 70$ & III & 0 & & + & & & Normal & Normal \\
\hline 2 & 24 & + & $120 / 80$ & III & 0 & & \pm & & & Normal & I Wave \\
\hline 3 & 50 & 0 & $110 / 80140 / 100$ & III & 0 & + & +++ & & & L.B.B.Bl. & Normal \\
\hline 4 & 41 & + & $130 / 70$ & II-III & 0 & + & + & & & L.V.t & Early V peak \\
\hline 5 & 50 & $?$ & $200 / 120$ & III & 0 & & +++ & & & L.V. + & Early V peak \\
\hline 6 & 47 & 0 & $180 / 110120 / 80$ & IV & + & + & +++ & + & + & L.V. + & Early V peak \\
\hline 7 & 70 & 0 & $175 / 115$ & IV & + & ++ & +++ & + & & L.V.t & Early V peak \\
\hline 8 & 55 & $\mathbf{0}$ & $140 / 100$ & III & 0 & ++ & ++ & + & + & L.V. + & Early V peak \\
\hline 9 & 20 & + & $125 / 70$ & III & 0 & + & \pm & & & Normal & Early V peak \\
\hline 10 & 30 & + & $120 / 80$ & III & 0 & + & \pm & & & L.V. + & Early V peak \\
\hline 11 & 55 & 0 & $165 / 100$ & III & 0 & ++ & +++ & & & L.V.t & Early V peak \\
\hline 12 & 32 & + & $150 / 85$ & III & $\mathbf{0}$ & & + & & & Normal & Early V peak \\
\hline 13 & 40 & + & $140 / 90$ & IV & 0 & + & \pm & & & Normal & Early V peak \\
\hline 14 & 43 & 0 & $135 / 85$ & III & 0 & + & + & & & Normal & I Wave \\
\hline
\end{tabular}


Group VI. Twenty-four patients who were thought to have pure mitral stenosis: 18 had sinus rhythm and 6 had auricular fibrillation. None had evidence of left ventricular enlargement unless there was associated aortic incompetence or hypertension, and in none was an apical systolic murmur heard.

Group VII. Seventeen patients who were thought to have mitral stenosis with incompetence. Sinus rhythm was present in 8 and auricular fibrillation in 9. All had apical systolic murmurs of Grade II or III intensity. In 2 patients with no evidence of aortic valve disease or hypertension, left ventricular enlargement was present.

\section{RESULTS}

\section{Group I. The Normal Esophageal Pulse}

Three distinctive patterns were found corresponding to ventricular, auricular, and aortic levels.

Ventricular Levels. The lower portion of the intrathoracic œsophagus is related to the aorta posteriorly and to the right. It may also be related anteriorly to the left ventricle, but the extent and closeness of this relationship is variable.

Fig. 2A shows the electrode at this level, and Fig. 2B and C the types of record obtained. The $P$ wave of the electrocardiogram is small and blunt. The pulse curve shows in early systole, a positive wave, which may be sustained as in Fig. 2B, or may decline as in Fig. 2C. The mode of production of these curves is uncertain. In controls such curves were found only at ventricular levels.

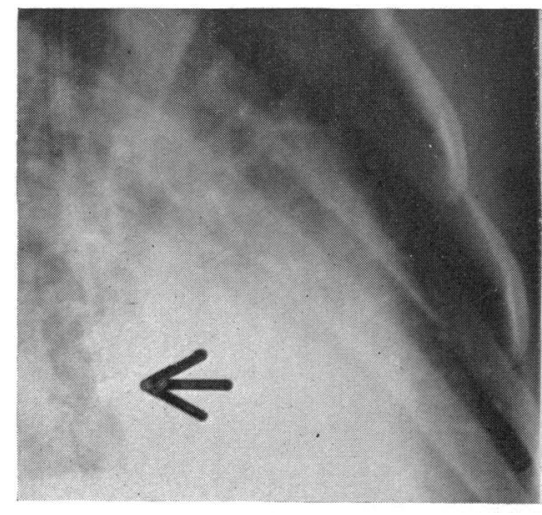

A

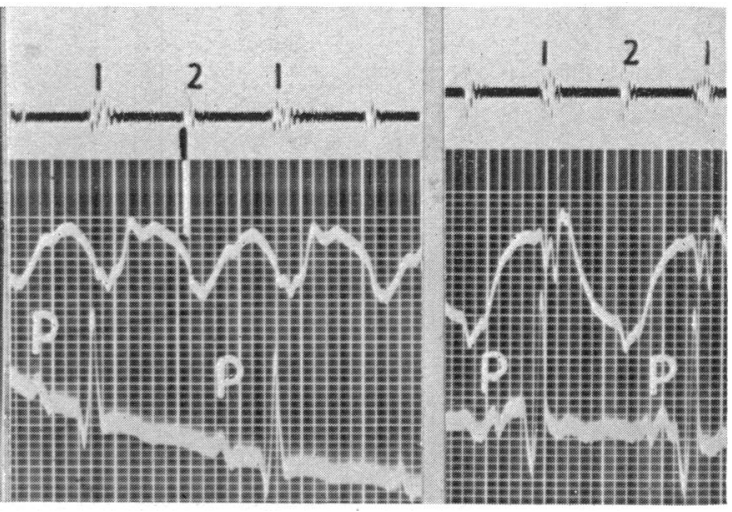

B
C

FIG. 2.-Control. (A) Skiagrams are taken in the right oblique position. The electrode is seen at the ventricular level. The tube extends $2 \mathrm{~cm}$. below it and therefore reaches nearly to the diaphragm. (B) The $\mathbf{P}$ wave is small and blunt, confirming the ventricular level. The sustained systolic positive wave is a normal finding at this level. (C) A variant found normally at "ventricular" levels.

Auricular Levels. The $\mathrm{P}$ wave is large and shows an intrinsicoid deflection, confirming the fact that the record was made from an auricular level (Fig. 3). The pulse shows three waves apparently analogous to those of the jugular phlebogram.

The $a$ wave begins shortly after the onset of $P$. It is variable in contour. Usually it is diphasic, an initial upstroke being followed by a prolonged and deeper negative phase. The upstroke may, however, predominate, or the wave may be entirely negative. An upstroke may be due to expansion of a portion of the auricle in which the muscle has not yet begun to contract. The negative phase is almost certainly due to recession of the contracting auricle from the œsophagus.

A record taken from a patient with complete heart block (Fig. 4) shows that the total duration of the $a$ wave may be as long as $\mathbf{0 . 3 0} \mathrm{sec}$. With normal conduction, therefore, waves due to ventricular systole are superimposed on the $a$ wave so that it is impossible to give measurements either of the duration of the $a$ wave or of the onset of ventricular waves. 


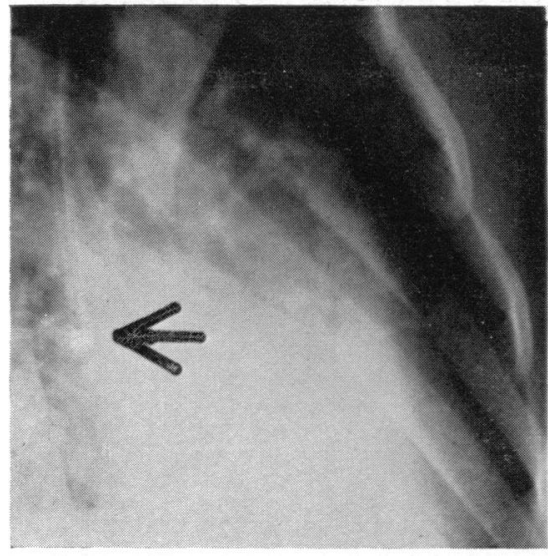

A

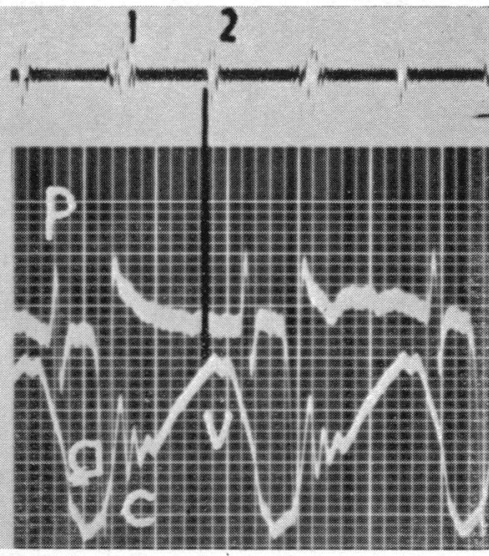

B

Fig. 3.-Control. (A) The tube extends nearly to the lowermost limit of the auricle. (B) The $\mathrm{P}$ wave shows an intrinsicoid deflection, confirming the auricular level. In this and subsequent records, a line has been drawn, the right edge of which corresponds with the beginning of the second heart sound. The apex of $v$ in controls was invariably found to the right of this line.

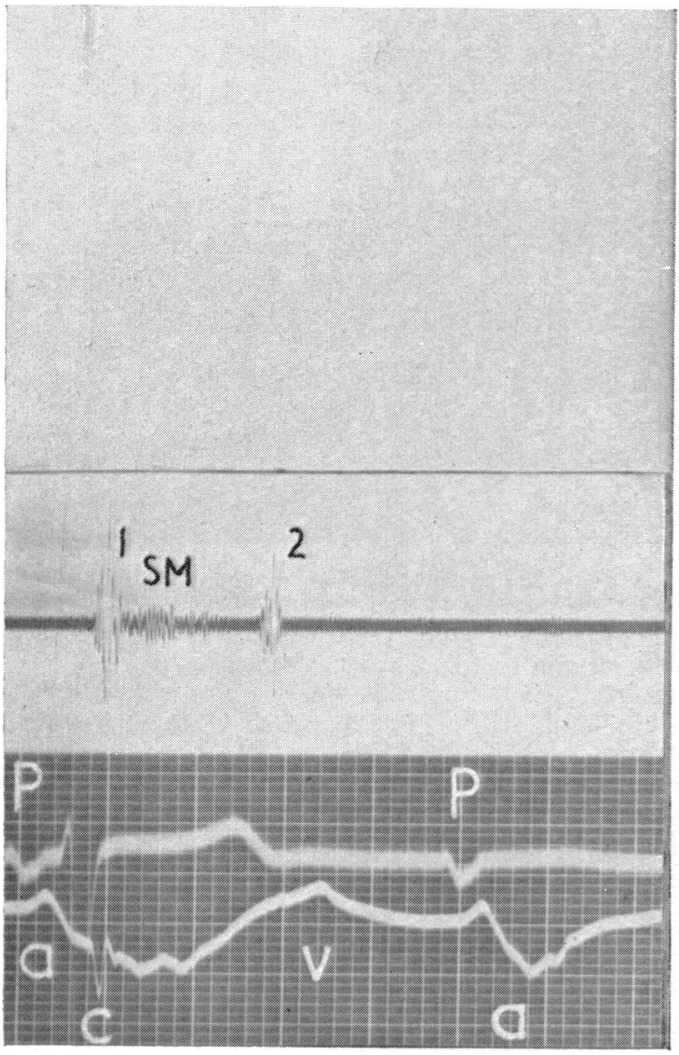

FIG. 4.-The record is from a patient with complete heart block and aortic stenosis. The $a$ wave is diphasicand its total duration is at least $0.30 \mathrm{sec}$. The first sound is accompanied by rapid deflections termed the " $c$ " wave. The electrocardiogram is lead V1.

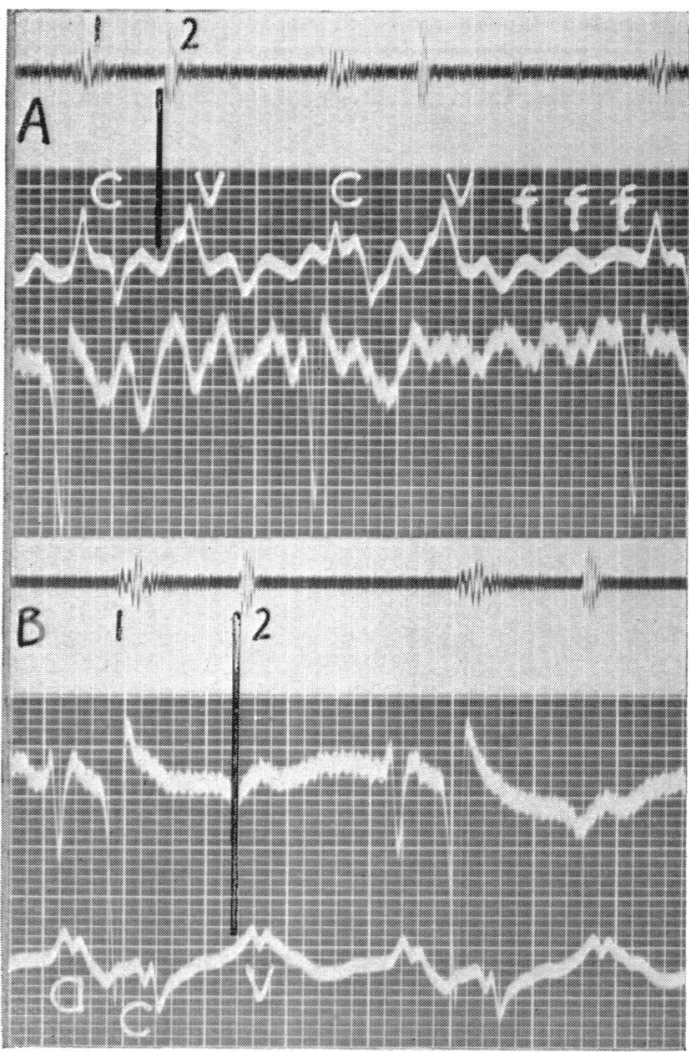

FIG. 5.-(A) A control with lone auricular fibrillation. The $c$ and $v$ waves are distorted by $f$ waves. (B) The same patient after restoration of sinus rhythm. 
The first sound is accompanied by rapid deflections termed the $c$ wave and these are absent when the first heart sound is absent. These deflections probably represent the vibrations of the first heart sound. The peak of the $v$ wave, which is notched, is never reached before the beginning of the second heart sound. It follows it in $0.01-0.08 \mathrm{sec}$. The $v$ wave begins to descend shortly after the beginning of the second heart sound. The rise and fall of the $v$ wave are probably due to filling and emptying of the auricle, respectively. The notch may be due to the vibrations of the second heart sound. It is probable that at auricular levels the form of the œsophageal pulse is largely determined by volume changes of the auricle together with vibrations of the first and second heart sounds.

Aortic Levels. Curves obtained at the level of the aortic arch are predominantly negative throughout systole and show a well-defined notch corresponding with the second heart sound. Taquini (1940) suggested that this curve may be due to a physiological unfolding of the aorta during systole. In elderly subjects in whom the œsophagus is displaced by an unfolded aorta, an approximation to the aortic level pattern may be found at auricular levels.

\section{Group II. Left Ventricular Hypertrophy}

All the patients in this group showed normal curves.

\section{Group III. Auricular fibrillation}

In this condition, $a$ waves are absent and the $c$ and $v$ waves usually show the configurations already described. Sometimes the $c$ waves are exaggerated. This may occur whether or not the record is distorted by $f$ waves as in Fig. 5A. Exaggeration of the $c$ waves may be partly due to the fact that they are unopposed by a negative $a$ wave, and partly to the closure of the mitral valve on an auricle that has not emptied properly owing to fibrillation.

The curves from patients with hypertensive heart disease were similar to those from patients with lone auricular fibrillation, with the exception of the single case with congestive failure, which will be discussed in detail.

\section{Group IV. Innocent Systolic Murmurs}

All 9 subjects were found to have normal œsophageal pulse curves.

\section{Group V. Pure Mitral Incompetence}

Of 14 patients in this group, 2 showed curves indistinguishable from normal. Two patients showed the " insufficiency (I) wave" described by Taquini (1937) and Puddu and Sibilia (1942). This consisted of a positive systolic wave (I) following $c$ and occupying early systole (Fig. 6B).

Ten cases showed a different abnormality. The apex of $v$ preceded the second sound by $0 \cdot 01-0 \cdot 12 \mathrm{sec}$., usually about $0.03 \mathrm{sec}$. (Fig. 6A, C and D). The normal notch at the apex of $v$ thought to be due to the second sound was either absent or replaced by multiple vibrations apparently representing the systolic murmur. The general configuration of the curves is similar to that found by Lasser et al. (1952) in pure mitral incompetence.

In 4 of these cases the upstroke of $v$ was very much more rapid at its beginning than at its end. In controls (Fig. 6E, F, G, H) the reverse is usually but not invariably the case. The contour of the curves and early $v$ peak can be explained on the basis of mitral reflux. The upstroke of $v$ is thought to represent expansion of the filling auricle and the peak of $v$ is recorded when the auricle ceases to expand. When auricular filling is augmented by reflux the upstroke of $v$ will be more rapid in mid-systole than in late systole when ventricular ejection is diminishing. Furthermore, mitral incompetence may produce a high enough pressure in the auricle to cause momentary reversal of flow from the pulmonary veins. When this occurs, the auricle will cease to expand and the apex of $v$ will be recorded early.

This theory does not conflict with the view that mitral reflux may continue into early diastole (Wiggers and Feil, 1922) for if there is reversal of flow from auricle into pulmonary veins, the auricle need show no further increase in size. The highest point of $v$ is recorded at the instant this reversal occurs and once the reversed flow is established the curve may remain flat or even decline slightly from elastic recoil of the auricular walls.

If reversal of flow does not occur, the apex of the $v$ wave would presumably be recorded in the normal position following the second sound; for the auricle would continue to fill both from the pulmonary veins 


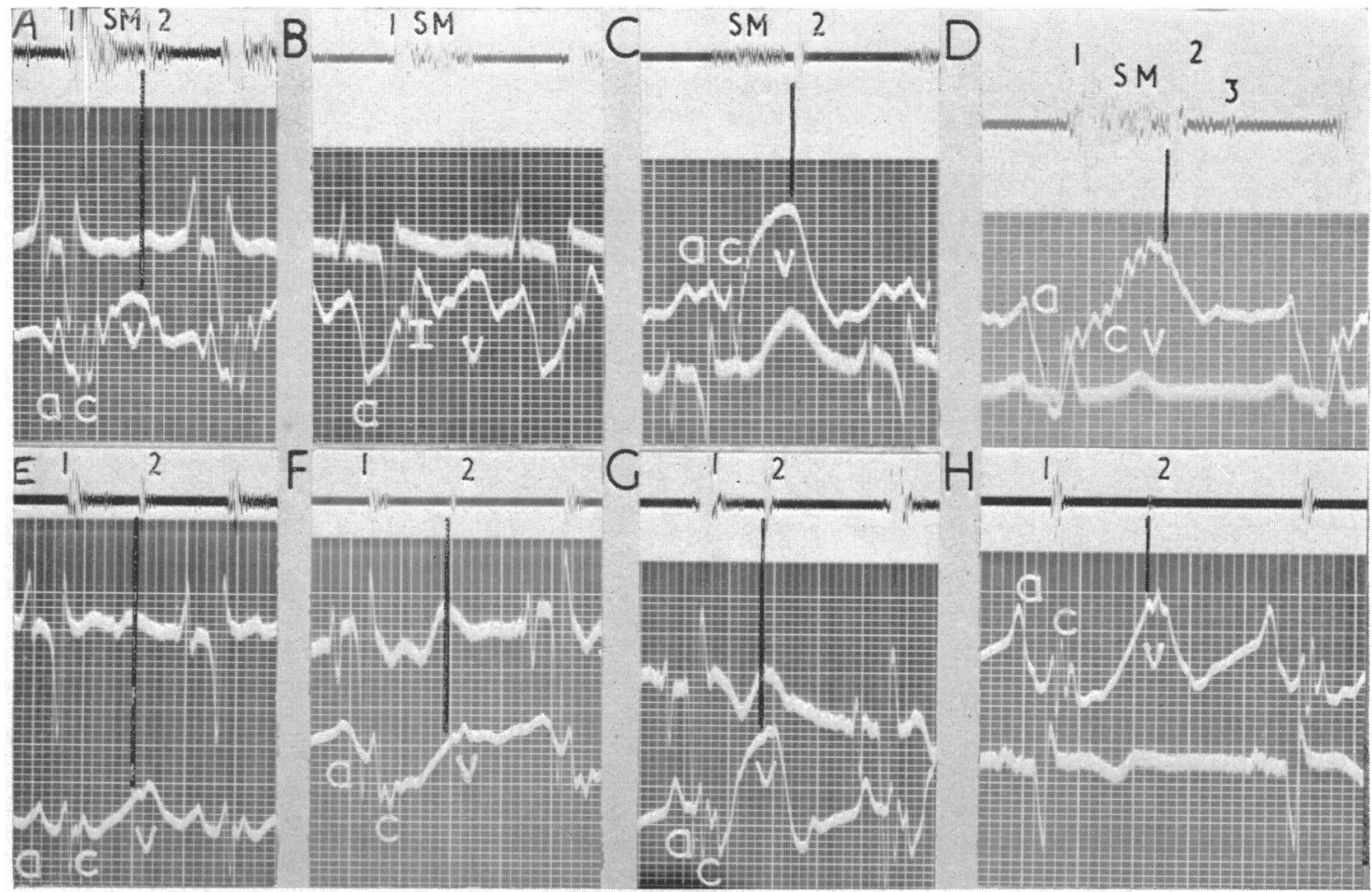

FIG. 6.-(A), (B), (C), and (D): mitral incompetence: Cases 12,10, 8, and 9 respectively. (E), (F), (G), and (H): Controls. In (A). (C), and (D), the apex of the $v$ wave occurs before the beginning of the second sound. The pulse contour in example (C) closely resembles that of the control (G). The time of the $v$ wave is the only clear point of distinction between them; (B) shows an I wave following directly on the $c$ wave.

and from the ventricle, until the mitral valve opened fully in early diastole. This may explain the finding of normal curves in two cases of mitral incompetence.

It might be thought that in cases of mitral incompetence in whom the timing of the $v$ peak was normal, the contour of the upstroke of $v$ would be diagnostic. Fig. 6G, however, shows a control in which the $v$ wave rises more rapidly at its beginning than at its end; its contour closely resembles the abnormal curve in Fig. $6 \mathrm{C}$. Only the relationship of the $v$ peak to the second sound enables the certain differentiation of the normal from the abnormal curve.

\section{Group VI. Pure Mitral Stenosis}

Of the 24 patients in this group, 9 curves were normal and one was doubtful. The remaining patients showed distortion of the $v$ wave. In some instances (Fig. 7B) the distortion was indistinguishable from the I wave previously described, in others the resemblance was less close (Fig. 7A). The distortion often resulted in the peak of the $v$ preceding the second sound (Fig. 7A).

In 6 cases the $v$ wave was grossly distorted and a sustained systolic positive wave approximating to a plateau form was present (Fig. 7C). These curves were found in 3 of the 6 cases with auricular fibrillation but in only 3 of the 18 cases with sinus rhythm. Necropsy of one of these patients showed tight mitral stenosis and no left ventricular hypertrophy. The essential factor in the production of this curve is probably auricular stasis. This is further discussed below.

\section{Group VII. Mitral Stenosis with Incompetence}

Fourteen of the 16 patients showed abnormalities similar to those found in pure mitral stenosis and 2 were normal. Sustained $c v$ waves were found in 5 of 9 cases with auricular fibrillation. This frequency is similar to that in pure mitral stenosis with auricular fibrillation. 


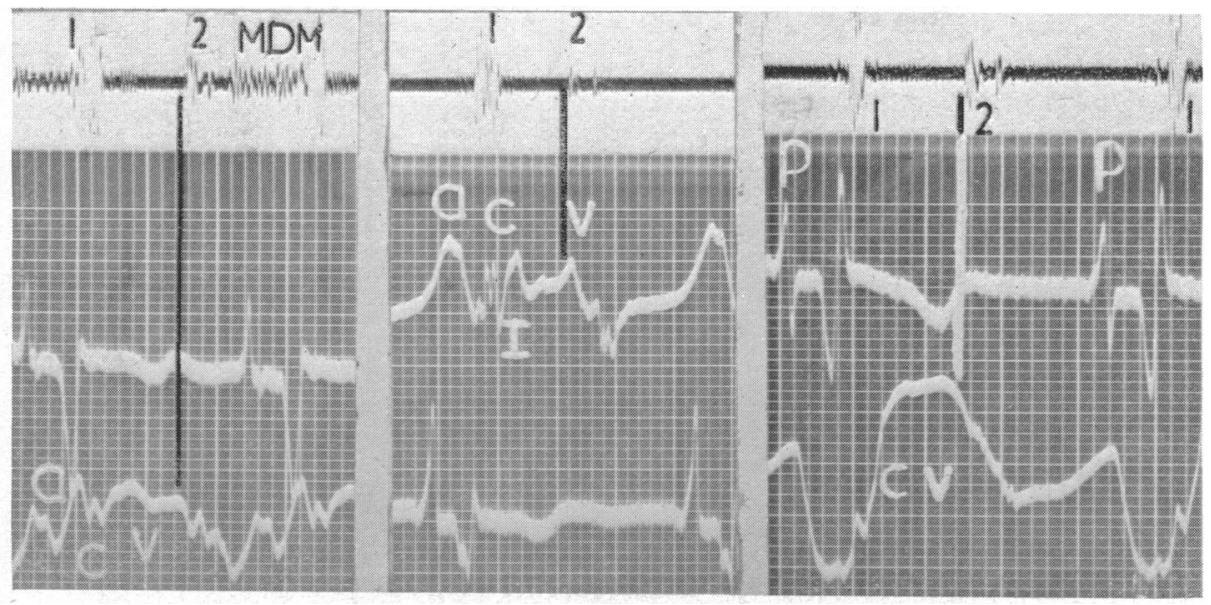

A

B

C

FIG. 7.-Examples of abnormalities found in pure mitral stenosis. (A) The $v$ wave is distorted. (B) An I wave follows the $c$ wave. (C) There is a systolic plateau $c v$.

\section{Discussion}

The curves found in our control groups correspond in general configuration with those of other investigators (Rautenberg, 1907; Edens, 1910). The use of the phonocardiogram as a reference tracing has, however, enabled a clear distinction to be made between the curves obtained from controls and those from patients suspected clinically of mitral valve disease. In 10 of the 14 cases of mitral incompetence, the highest point of the $v$ wave was reached before the beginning of the second heart sound, and two patients showed the I wave described by previous authors. Esophageal pulse records can therefore be used to establish the diagnosis of mitral valve disease in patients with a systolic murmur alone. A normal œsophageal pulse record, however, does not exclude the diagnosis of mitral incompetence.

In Groups VI and VII the interpretation of the pulse records is more difficult. The sustained systolic $c v$ wave found in 6 cases of pure mitral stenosis is of particular interest. This type of wave has been recognized at fluoroscopy as a backward movement of the left auricular contour during systole and has been recorded with the electrokymograph. Both observations have led to the assumtion that the movement or wave was directly due to reflux from the ventricle to auricle (Lian $e t$ al., 1948; Luisada and Fleischner, 1948; McKinnon and Friedman, 1950; Segers, 1951; Heyer and Boone, 1952). The validity of this assumption has been challenged by Phillips (1949) and Froment et al. (1950) and the present study provides further evidence that it is incorrect.

Plateau waves were never found at auricular levels in pure mitral incompetence, but they were found in 6 cases of mitral stenosis with no clinical evidence of incompetence. In one of these necropsy showed tight mitral stenosis and no evidence of incompetence. It is not clear why plateau waves need be expected in mitral incompetence. A flat-topped wave in the asophageal pulse, electrokymogram, or pressure pulse shows that no further change in volume, movement or pressure is occurring, whereas clinical evidence and the work of Wiggers (1922) suggest that reflux continues throughout systole.

Wynn et al. (1952) found systolic plateau waves in left auricular pulse records from patients with pure mitral stenosis and considered that they were not due to reflux. They suggested that the pressure rise at the beginning of ventricular systole was due to inward bulging of the mitral valve and floor of the auricle, and that the sustained character of this pressure rise was due to auricular stasis.

We have made similar observations in one of our controls - an 84-year-old man with auricular fibrillation and chronic congestive failure due to hypertensive and ischæmic heart disease. There 
was no evidence of mitral valve disease and no systolic murmur to suggest functional mitral incompetence. Plateau waves occurred only after the shorter diastolic pauses (Fig. 8A). The shortness of diastole must be presumed to have curtailed auricular emptying, so that very slight filling from the pulmonary veins during ventricular systole sufficed to fill the auricle completely and so produced a flat-topped curve.

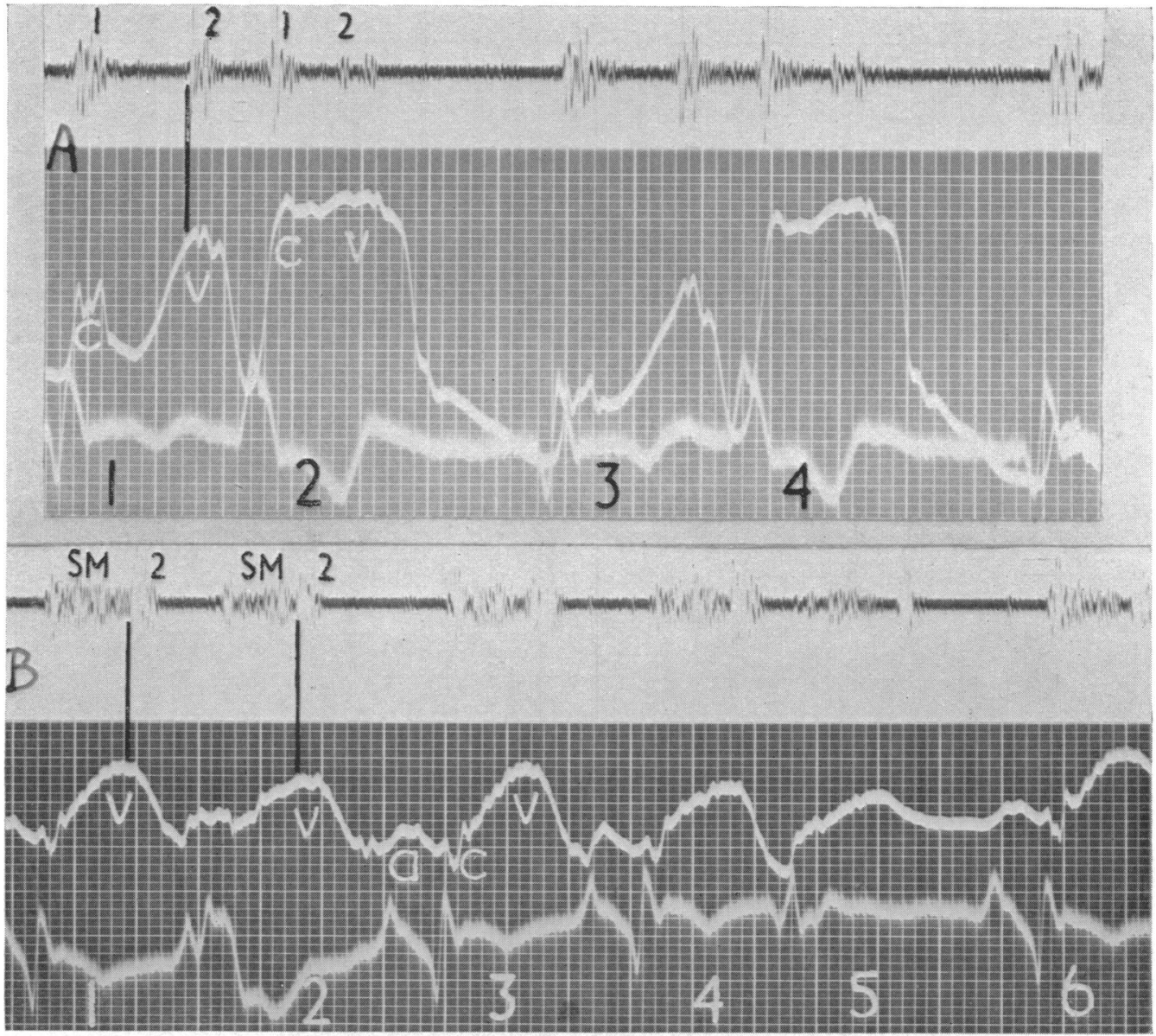

FIG 8.-(A) From an 84-year-old man with chronic congestive failure due to hypertensive and ischæmic heart disease with auricular fibrillation. In the 1st and 3rd beats the osophageal pulse shows the contours found normally in lone auricular fibrillation. The 2 nd and 4 th beats are premature ventricular contractions and produce systolic plateau waves of larger amplitude than the $c$ and $v$ waves of the preceding beat. (B) From a patient with mitral incompetence. The 2 nd and 5 th beats are premature ventricular contractions and are accompanied by $v$ waves smaller than those of the preceding beat.

In mitral incompetence, abbreviation of diastole would be expected to have, and was in fact found to have, a reverse effect (Fig. 8B). Short diastolic pauses are followed by low $v$ waves, the longer pauses by larger $v$ waves. This is presumably due to the fact that a long diastole allows greater ventricular filling, which results in a more powerful subsequent contraction and a correspondingly greater volume of reflux.

These observations, together with the fact that in mitral stenosis plateau waves are commoner in patients with auricular fibrillation than in those with sinus rhythm, strongly suggest that auricular stasis is the fundamental cause of the abnormality. The shape of the curve is in harmony with this 
explanation since the flat-topped wave suggests an unchanging volume. The contrast between this curve and the curve of pure mitral incompetence is shown in Fig. 9A and B.

If this interpretation proves to be correct, a plateau wave in patients with mitral stenosis and sinus rhythm should suggest the presence of a tight stenosis. When auricular fibrillation or congestive failure contributes to auricular stasis a less severe degree of stenosis may suffice to produce the curve, and auricular fibrillation and failure together may produce the curve in the absence of stenosis if diastole is short. If an extended study establishes these correlations, the œsophageal pulse may prove valuable in the selection of patients for valvotomy.

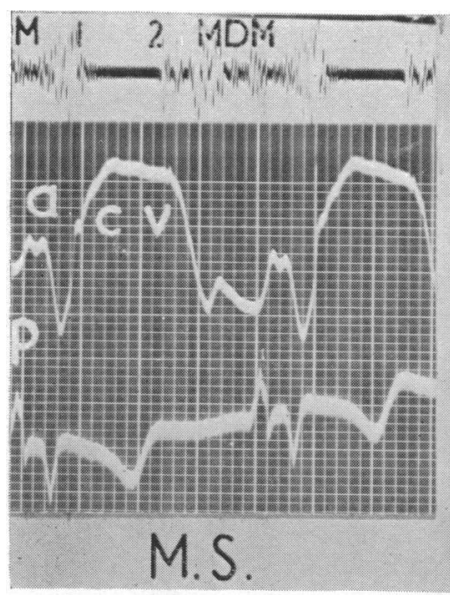

A

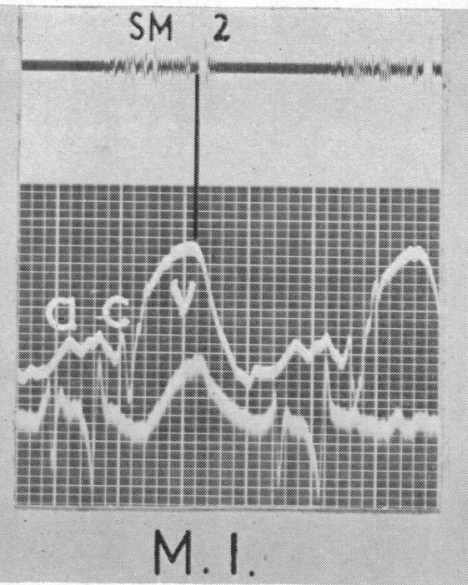

B

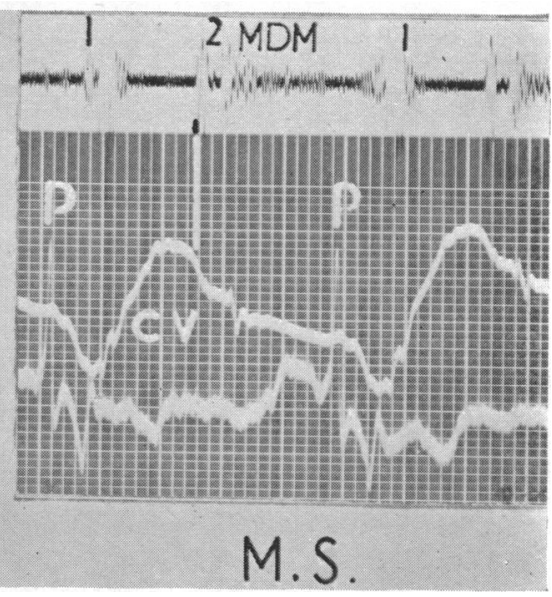

C

FIG. 9.-(A) The plateau wave that is thought to depend on auricular stenosis. (B) A typical curve of pure mitral incompetence. (C) A curve of pure mitral stenosis closely resembling (B).

The diagnosis of incompetence in the presence of stenosis remains difficult. Lasser et al. (1952) suggested that distinctive patterns could be recognized in pure mitral incompetence, pure mitral stenosis, and mitral stenosis with incompetence. Our findings are at variance with these conclusions. We have found the plateau wave stated to be characteristic of pure mitral stenosis, in 5 patients with combined stenosis and incompetence, and the curve claimed to be characteristic of the latter condition in only one of sixteen cases. Curves were found in pure mitral stenosis that closely resembled those from pure mitral incompetence (compare Fig. 9B and C). For these reasons we feel that the three conditions cannot be differentiated with certainty on the basis of pulse tracings alone, and that an abnormal pulse curve is diagnostic only of mitral valve disease. A systolic plateau wave in the absence of auricular fibrillation is, however, suggestive of a tight mitral stenosis. In congestive failure, an abnormal pulse curve may be found in the absence of mitral valve disease.

\section{SUMMARY AND CONCLUSIONS}

The œsophageal pulse was recorded simultaneously with the electrocardiograph and heart sounds in 119 subjects. There were 55 patients with mitral valve disease, an equal number of controls, and 9 subjects with innocent systolic murmurs. The control group included patients with aortic valve disease, lone auricular fibrillation, hypertensive heart disease with and without auricular fibrillation, and 27 normal subjects.

In the control group $a, c$ and $v$ waves analogous to those of the jugular phlebogram were found at auricular levels. With the exception of the single case with congestive failure the apex of the $v$ wave never preceded the second heart sound. 
Nine subjects thought to have innocent systolic murmurs showed normal curves.

Of 14 patients with a clinical diagnosis of pure mitral incompetence 12 showed abnormal pulse curves. In 10 the apex of $v$ preceded the second heart sound. In 2 an abnormal positive wave occurred in early systole. The œsophageal pulse can therefore provide proof of mitral valve disease in patients with a systolic murmur alone, although a normal œsophageal pulse does not exclude the diagnosis of mitral incompetence.

Of 41 patients with mitral stenosis, 20 showed abnormalities of the pulse curve whether or not there was clinical associated incompetence. The diagnosis of incompetence in the presence of stenosis cannot be made with certainty from the pulse tracing alone.

Systolic plateau waves were found in 5 patients who had auricular fibrillation and mitral stenosis and incompetence, and in 6 patients with clinically pure mitral stenosis. Necropsy of one of the latter showed a tight stenosis and no left ventricular hypertrophy. It is suggested that such curves do not depend on reflux but on auricular stasis and that they may be found to give an indication of the severity of the stenosis.

I am indebted to Dr. Jenner Hoskin and Dr. Frances Gardner for their helpful criticism and advice, and to Dr. Paul Wood for his kindness in allowing me to study two of his patients.

I wish to thank Miss B. Robinson, Mr. D. Edwards, Miss I. Morgan and the Photographic Department of the Hospital for technical assistance.

\section{REFERENCES}

Bard, L. (1912). Sem. médicale, Paris, 32, 253.

Brown, W. H. (1936). Amer. Heart J., 12, 1.

Edens, E. (1910). Dtsch. Arch. klin. Med., 100, 221.

Froment, R., Gonin, A., and Gallavardin, L. (1950). Arch. Mal. Coeur., 43, 678.

Heyer, H. E. and Boone, B. R. (1952). Amer. Heart J., 44, 458.

Janowski, W. (1910). Z. klin. Med., 62, 371.

Lasser, R. P., Epstein, B., and Loewe, L. (1952). Amer. Heart J., 44, 681.

Levine, S. A. (1933). J. Amer. med. Ass., 101, 436.

Lewis, T. (1925). Mechanism and Graphic Registration of the Heart Beat. 3rd. ed., p. 22. Shaw, London.

Lian, C. (1909). Arch. Mal. Coeur., 2, 391.

- Facquet, J., and Minot, G. (1948). Arch. Mal. Coeur., 41, 727.

Luisada, A. A., and Fleischner, F. G. (1948). Amer. J. Med., 4, 791.

McKinnon, J. B., and Friedman, B. (1950). Circulation, 2, 572.

Minkowski, W. (1907). Z. klin. Med., 62, 371.

Phillips, E. (1949). Permanente Fdn. med. Bull., 7, 25.

Puddu, V., and Sibilia, D. (1942). Cuore e Circul., 26, 2.

Rautenberg, E. (1907). Dtsch. Arch. klin. Med., 91, 251.

Segers, M. (1951). Brux. méd., 31, 1657.

Taquini, A. C. (1937). Rev. Soc. Argent. Biol., 13, 17 and 57.

(1940). Amer Heart J., 20, 129.

Wiggers, C. J., and Feil, H. (1922). Heart, 9, 149.

Wynn, A., Matthews, M. B., McMillan, I. K. R., and Daley R. (1952). Lancet, $2,216$. 